\title{
Optimal Body Size and Energy Expenditure during Winter: Why Are Voles Smaller in Declining Populations?
}

\author{
Torbjørn Ergon, ${ }^{1, *}$ John R. Speakman, ${ }^{2, \dagger}$ Michael Scantlebury, ${ }^{2, \uparrow}$ Rachel Cavanagh, ${ }^{3, \$}$ and Xavier Lambin ${ }^{4, \|}$
}

1. Centre for Ecological and Evolutionary Synthesis, Department of Biology, University of Oslo, P.O. Box 1050 Blindern, 0316 Oslo, Norway;

2. Integrative Physiology, School of Biological Sciences, University of Aberdeen, Tillydrone Avenue, Aberdeen AB24 2TZ, Scotland, United Kingdom;

3. Naturebureau International, 36 Kingfisher Court, Hambridge Road, Newbury, Berkshire RG14 5SJ, United Kingdom;

4. Aberdeen Population Ecology Research Unit (APERU), School of Biological Sciences, University of Aberdeen, Tillydrone Avenue, Aberdeen AB24 2TZ, Scotland, United Kingdom

Submitted December 18, 2002; Accepted August 18, 2003;

Electronically published March 9, 2004

Online enhancement: figure.

ABSTRACT: Winter is energetically challenging for small herbivores because of greater energy requirements for thermogenesis at a time when little energy is available. We formulated a model predicting optimal wintering body size, accounting for the scaling of both energy expenditure and assimilation to body size, and the trade-off between survival benefits of a large size and avoiding survival costs of foraging. The model predicts that if the energy cost of maintaining a given body mass differs between environments, animals should be smaller in the more demanding environments, and there should be a negative correlation between body mass and daily energy expenditure (DEE) across environments. In contrast, if animals adjust their energy intake according to variation in survival costs of foraging, there should be a positive correlation between body mass and DEE. Decreasing temperature always increases equilibrium DEE, but optimal body mass

* E-mail: torbjorn.ergon@bio.uio.no.

${ }^{\dagger}$ Aberdeen Centre for Energy Regulation and Obesity (ACERO), Rowett Research Institute, Bucksburn, Aberdeen AB24 9BS, Scotland; e-mail: j.speakman@abdn.ac.uk.

₹ Department of Zoology and Entomology, Mammal Research Institute, University of Pretoria, Pretoria 0002, South Africa; e-mail: m.scantlebury@zoology.up.ac.za.

`E-mail: rachel@naturebureau.co.uk.

"| E-mail: x.lambin@abdn.ac.uk.

Am. Nat. 2004. Vol. 163, pp. 442-457. (c) 2004 by The University of Chicago. 0003-0147/2004/16303-20460\$15.00. All rights reserved. may either increase or decrease in colder climates depending on the exact effects of temperature on mass-specific survival and energy demands. Measuring DEE with doubly labeled water on wintering Microtus agrestis at four field sites, we found that DEE was highest at the sites where voles were smallest despite a positive correlation between DEE and body mass within sites. This suggests that variation in wintering body mass between sites was due to variation in food quality/availability and not adjustments in foraging activity to varying risks of predation.

Keywords: life-history evolution, phenotypic plasticity, Bergmann's rule, doubly labeled water, small rodent cycles, AIC multimodel inference.

Theories for the evolution of body size have mostly been concerned with interspecific patterns and geographical trends among populations (e.g., James 1970; Speakman 1996; Ashton et al. 2000). Within populations, larger individuals are often assumed to be fitter because size enhances survival and reproductive success (Cuthill and Houston 1997; Blanckenhorn 2000). While the evidence for selection favoring larger adult body size is overwhelming, mechanisms for counterbalancing selection against large body size are less obvious and generally lack empirical evidence (Blanckenhorn 2000). In this article we direct attention to energetic constraints and survival costs during foraging. In particular we aim to explain variation in wintering body size within populations of small mammals.

Winter is an energetically challenging season for small mammalian herbivores in northern climates: at the same time that ambient temperature declines and more energy is required for thermogenesis (McDevitt and Speakman 1994; Jackson et al. 2001), primary production also declines, and less energy is available in the food plants. While hibernating animals prepare for the winter by accumulating fat reserves (Mrosovsky 1978), many small mammals that remain active in the winter show seasonal changes in their structural size alongside other physiological adjustments.

Whether larger or smaller body size should be favored under winter conditions is not obvious. On the one hand, larger bodies are more robust against low temperatures 
(Speakman 1996; Jackson et al. 2001) and periods of insufficient energy supply (Millar and Hickling 1990). On the other hand, smaller animals have lower absolute energy requirements and may spend more time in their warm nests (Madison 1984; Hayes et al. 1992), where they may also be less exposed to predation (Lima 1998a). Indeed, different species respond differently to shortened day length preceding the winter. For example, collared lemmings (Dicrostonyx groenlandicus, Traill) living in the high arctic develop a larger adult body size before the winter than they do in the summer (e.g., Nagy and Negus 1993; Gower et al. 1994). Many species of voles, however, maintain a smaller body size in the winter than in the summer. Immature voles that do not reproduce in their year of birth suspend growth before the winter and do not resume growing until they become reproductively active in the following spring (e.g., Boonstra 1989; Hansson 1990; Gliwicz 1996). Further, large individuals that have matured typically reduce their body mass by $20 \%-40 \%$ before the winter (e.g., Iverson and Turner 1974; Hansson 1992; Aars and Ims 2002). Shrews show similar seasonal changes in body size and are known to shrink even skeletal structures (Dehnel 1949; Crowcroft and Ingles 1959).

These seasonal patterns in body-size development are known to be cued by changes in photoperiod (Iverson and Turner 1974; Spears and Clarke 1988; Bronson and Heideman 1994; Kriegsfeld and Nelson 1996) and may thus be assumed to represent adaptive preparations for the winter (day length per se is unlikely to restrict microtines food intake, as they feed regularly both day and night). Reduced winter body mass is suggested to be an energy-saving adaptation that enhances survival when food supply is poor (e.g., Dark and Zucker 1983; Hansson 1990).

Body mass in northern vole populations varies not only seasonally. Large variations in body mass of animals in the same season and life-history stage also occur between years and habitats. This is most evident in periodically fluctuating populations: animals are larger during the increase and peak phases of the fluctuations than in the declining and low phases. Such patterns in body mass variation, known as the "Chitty effect" (Chitty 1952; Boonstra and Krebs 1979), have been most widely demonstrated for breeding adults in the summer season (reviews in Krebs and Myers 1974; Taitt and Krebs 1985; Norrdahl and Korpimäki 2002), but also overwintering nonbreeding animals have been found to be larger during population increase (Tast 1984; Hansson 1995; Ergon et al. 2001). Although such variation in body size and other life-history traits of small rodents has been demonstrated mainly to be due to phenotypic plasticity rather than genetic differences (Boonstra and Hochachka 1997; Hansen and Boonstra 2000; Ergon et al. 2001), the ecological and physiological mechanisms are largely unresolved.
Below we formalize a model predicting optimal wintering body size and energy expenditure of nonbreeding small mammals that remain actively foraging throughout the winter. We derive predictions about the relationship between body mass and daily energy expenditure (DEE) that should be observed when optimal body mass is modulated by different mechanisms. Finally, we compare these predictions to measurements of DEE, obtained by the doubly labeled water technique (Speakman 1997a), of field voles (Microtus agrestis, L.) in four different field sites that varied in wintering body mass as well as other life-history traits and population development (see specific hypotheses below).

\section{The Model}

Large body size $(M)$ renders survival advantages in a winter environment for two main reasons. First, larger animals have a higher thermogenic capacity helping them to sustain body temperature during cold periods (Speakman 1996; Jackson et al. 2001). Second, larger animals have a higher fasting endurance enabling them to survive for longer periods with negative energy balance (e.g., periods of low ambient temperature; Calder 1984; Lindstedt and Boyce 1985; Millar and Hickling 1990).

Fitness may also depend on the proportion of time spent foraging $(P)$, as animals are presumably more exposed to predation while foraging (Oksanen and Lundberg 1995; Lima 1998a). Hence, if body size $(M)$ and foraging time $(P)$ were independent (i.e., no trade-off), fitness would increase with higher $M$ and lower $P$. However, there is presumably a trade-off between high $M$ and low $P$ because larger animals require a higher rate of energy intake and hence more time spent foraging.

The approach taken here is first to derive a function relating fitness to $M$ and $P$ in the absence of trade-offs. The fitness isoclines (points with equal fitness) given by this function may be plotted in the plane spanned by $M$ and $P$, which produces an "adaptive landscape" on which the trade-off curves (attainable values of $\{M, P\}$ ) are superimposed. Optimal body mass, $M^{*}$, is the point on the trade-off curve with highest fitness (see fig. $1 D$ and, e.g., Sibly 1991 for the general approach).

\section{Fitness Function}

Small mammals do not normally reproduce in the winter, and we assume that postwinter reproduction and survival are independent of $M$ and $P$ (see "Discussion"). Hence, fitness, $W$, is set to equate winter survival. Winter survival is given by one component depending on $M, S_{\mathrm{m}}(M)$, a fixed survival component $s_{\mathrm{f}}$ during the proportion of time spent foraging, $P$, and a fixed survival component $s_{\mathrm{n}}$ during 


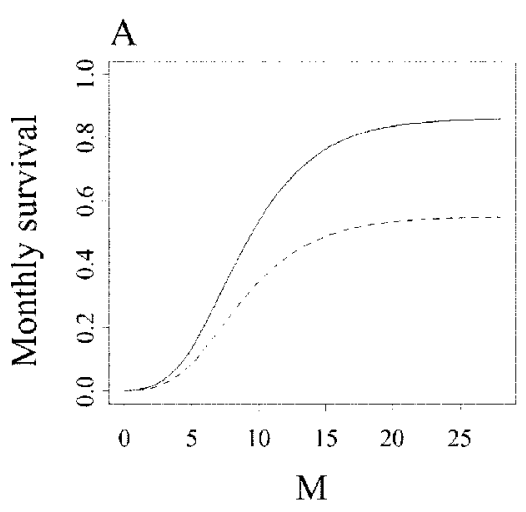

D

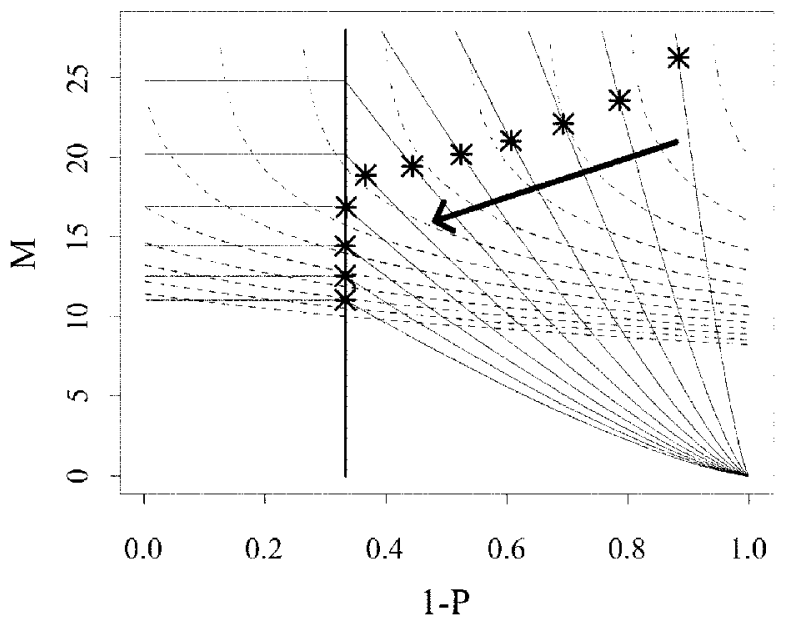

B

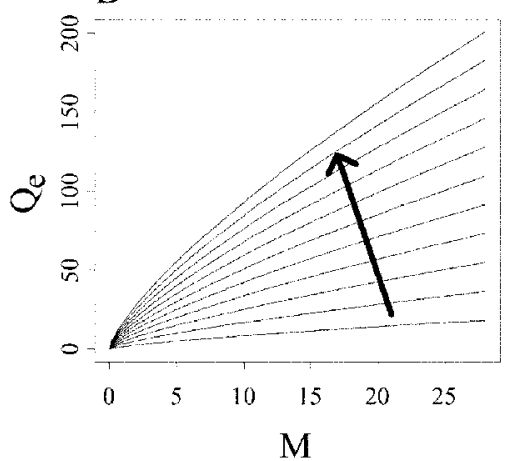

$\mathrm{M}$

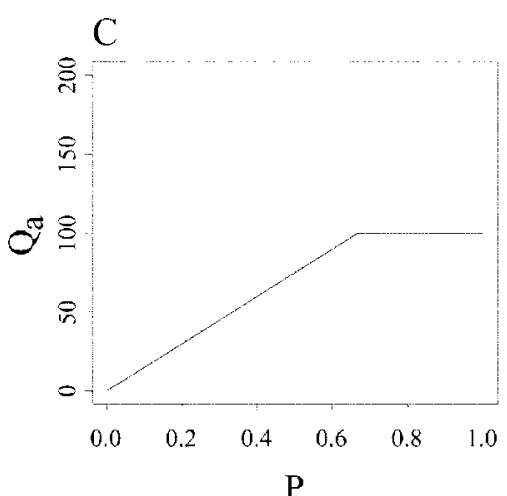

$\mathrm{E}$

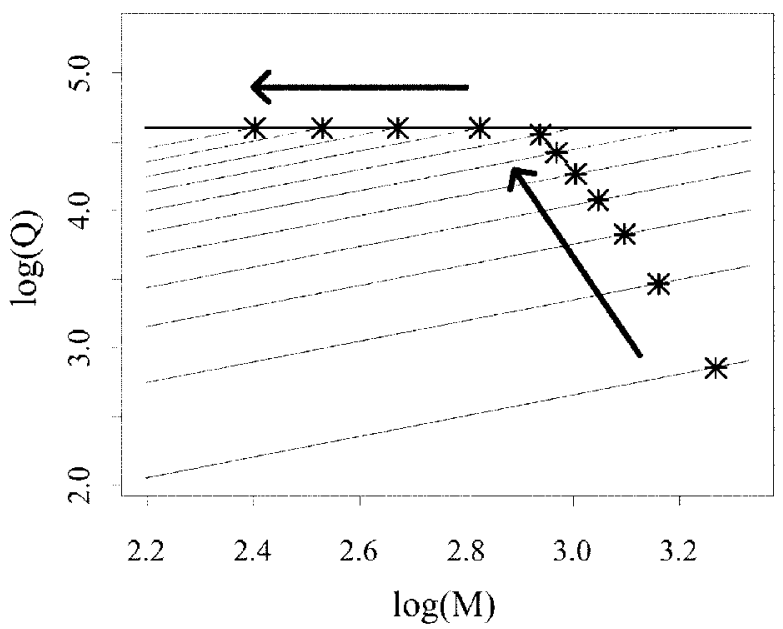

Figure 1: Model for optimal body mass of nonbreeding wintering small mammals. A, Fitness equals survival, which depends on both body mass $(M)$ and proportion of time spent foraging ( $P$; see eq. [3]). Solid line, rate of survival during the time not foraging (plotted on a monthly scale $\left.\left(S_{\mathrm{m}}[M] s_{\mathrm{n}}\right)^{30}\right)$; stippled line, survival rate when foraging $\left(\left(S_{\mathrm{m}}[M] s_{\mathrm{f}}\right)^{30}\right.$; see eq. [1]). $B$, Energy required to maintain a given $M, Q_{\mathrm{e}}(M)$ (eq. [5]), plotted for different values of $a_{\mathrm{e}}$ (arrow indicates increasing $a_{\mathrm{e}}$ ). $C$, Energy assimilation depending on $P$ and $M$ (eq. [6]). $D$, Optimal $M$ and $1-P$ for different trade-off curves in one "adaptive landscape." Fitness isoclines (eq. [4]) are plotted as stippled contours (higher fitness with higher $M$ and $1-P$ ). Trade-off curves (eq. [8]) for the different values of $a_{\mathrm{e}}$ plotted in $B$ are given as solid lines. Maximum fitness on each trade-off curve is indicated by an asterisk (found numerically). Maximum rate of assimilation, $q_{\max }$ (see eq. [6]), is reached to the left of the thick line. E, Energy expenditure $\left(Q^{*}=Q_{e}\left(M^{*}\right)=Q_{a}\left(M^{*}, P^{*}\right)\right)$ and body mass $\left(M^{*}\right)$ at optimum (asterisks) in the different environments (values of $a_{\mathrm{e}}$ ). Thin lines are $Q_{e}(M)$ plotted in $B$. Thick line, maximum energy assimilation given by $q_{\max }=a_{\mathrm{m}} M^{b_{\mathrm{m}}}$ (eq. [7]). Arrows in panels $B, D$, and $E$ indicate increasing energetic demands of the environment (increasing values of $a_{\mathrm{e}}$ ). Parameter values are realistic for voles when $M$ is given in grams and $Q$ is given in kilojoules per day: $s_{\mathrm{n}}=0.995, s_{\mathrm{f}}=0.980, b_{\mathrm{s}}=0.28, a_{\mathrm{s}}=5 b_{\mathrm{s}}, W=\{0.970,0.972, \ldots, 0.998\}, a_{\mathrm{e}}=\{1.5,3.0, \ldots, 16.5\}, b_{\mathrm{e}}=0.75, a_{\mathrm{c}}=150$, $b_{\mathrm{c}}=0, a_{\mathrm{m}}=100, b_{\mathrm{m}}=0$.

the proportion of time not foraging, $1-P$. Hence, survival rate while foraging is $S_{\mathrm{m}}(M)_{\mathrm{f}}$, and survival rate when not foraging is $S_{\mathrm{m}}(M) s_{\mathrm{n}}$. Total survival, or fitness, is thus

$$
W=\left[S_{\mathrm{m}}(M) s_{\mathrm{f}}\right]^{P}\left[S_{\mathrm{m}}(M) s_{\mathrm{n}}\right]^{1-P}=S_{\mathrm{m}}(M) s_{\mathrm{f}}^{P_{\mathrm{n}}^{1-P}} .
$$

We choose the logistic function for $S_{\mathrm{m}}(M)$,

$$
S_{\mathrm{m}}(M)=\frac{1}{1+e^{-a_{\mathrm{s}}-b_{\mathrm{s}} M}}
$$

where $a_{\mathrm{s}}$ and $b_{\mathrm{s}}$ are the intercept and slope of $\operatorname{logit}\left(S_{\mathrm{m}}[M]\right)$ on $M$. Substituting this into equation (1) gives the final expression for fitness as a function of $M$ and $P$,

$$
W(M, P)=\frac{s_{\mathrm{f}}^{P} s_{\mathrm{n}}^{1-P}}{1+e^{-a_{\mathrm{s}}-b_{\mathrm{s}} M}} .
$$

The parameter $b_{\mathrm{s}}$ is positive, and $0<s_{\mathrm{f}}<s_{\mathrm{n}}<1$. The variables $M$ and $P$ are positive, and $0<P<1$. Thus, $W$ increases with higher $M$ and lower $P$. 
Fitness isoclines in the adaptive landscape spanned by $P$ and $M$ are found by solving equation (3) for $M$

$$
M=g(P)=\frac{-a_{\mathrm{s}}-\log \left\{\left[\left(s_{\mathrm{f}}^{P_{\mathrm{n}}^{1-P}}\right) / W\right]-1\right\}}{b_{\mathrm{s}}} .
$$

This fitness function implies that fitness is sensitive to a change in $M$ at low $M$ and sensitive to a change in $P$ at high $M$. At intermediate $M$, fitness is sensitive to both $M$ and $P$ (fig. $1 A, 1 D$ ).

\section{Trade-off Function}

At stable body mass, energy assimilation $\left(Q_{\mathrm{a}}\right)$ must equal energy expenditure $\left(Q_{e}\right)$. Hence, the trade-off function describing all possible combinations of $M$ and $P$ is found by requiring that rate of energy assimilation depending on $M$ and $P, Q_{a}(M, P)$, equals energy required to maintain a given $M, Q_{e}(M)$.

For $Q_{e}(M)$ we use the usual power function for allometric scaling:

$$
Q_{\mathrm{e}}(M)=a_{\mathrm{e}} M^{b_{\mathrm{e}}}
$$

(fig. 1B).

We further assume that $Q_{\mathrm{a}}(M, P)$ increases proportionally with $P$ until maximum assimilation is reached (fig. 1C). Hence,

$$
Q_{\mathrm{a}}(P)=\left\{\begin{array}{ll}
c P, & \text { when } P \leq \frac{q_{\max }}{c} \\
q_{\max }, & \text { when } P<\frac{q_{\max }}{c}
\end{array} .\right.
$$

Both rate of energy assimilation during the time spent foraging, $c$, and maximum energy assimilation, $q_{\max }$, may be scaled to $M$. Substituting $c=a_{\mathrm{c}} M^{b_{\mathrm{c}}}$ and $q_{\max }=$ $a_{\mathrm{m}} M^{b_{\mathrm{m}}}$ into equation (6) gives an expression for $Q_{\mathrm{a}}(M, P)$ in its most general form

$$
Q_{\mathrm{a}}(M, P)=\left\{\begin{array}{l}
a_{\mathrm{c}} M^{b_{\mathrm{c}}} P, \text { when } P \leq \frac{a_{\mathrm{m}} M^{b_{\mathrm{m}}}}{a_{\mathrm{c}} M^{b_{\mathrm{c}}}} . \\
a_{\mathrm{m}} M^{b_{\mathrm{m}}} P, \text { when } P>\frac{a_{\mathrm{m}} M^{b_{\mathrm{m}}}}{a_{\mathrm{c}} M^{b_{\mathrm{c}}}}
\end{array}\right.
$$

Solving $Q_{\mathrm{e}}(M)=Q_{\mathrm{a}}(M, P)$ for $M$ gives the trade-off function

$$
M=h(P)= \begin{cases}\left(\frac{a_{\mathrm{c}}}{a_{\mathrm{e}}}\right)^{1 /\left(b_{\mathrm{e}}-b_{\mathrm{c}}\right)}, & \text { when } P \leq \frac{a_{\mathrm{m}} M^{b_{\mathrm{m}}}}{a_{\mathrm{c}} M^{b_{\mathrm{c}}}} \\ \left(\frac{a_{\mathrm{m}}}{a_{\mathrm{e}}}\right)^{1 /\left(b_{\mathrm{e}}-b_{\mathrm{m}}\right)}, & \text { when } P>\frac{a_{\mathrm{m}} M^{b_{\mathrm{m}}}}{a_{\mathrm{c}} M^{b_{\mathrm{c}}}}\end{cases}
$$

All parameters are positive, and the exponents $b_{\mathrm{e}}, b_{\mathrm{c}}$, and $b_{\mathrm{m}}$ are $\leq 1$. In the lower interval of $P, M=h(P)$ will decrease when foraging time $(P)$ is reduced (i.e., there is a trade-off between high $M$ and low $P$ ) as long as $b_{c}<$ $b_{\mathrm{e}}$. If $b_{\mathrm{c}}>b_{\mathrm{e}}$, then $h(P)$ will increase to $+\infty$ as $P$ approaches 0 , and there is no trade-off. Hence, the model does not apply for cases where $b_{\mathrm{c}}>b_{\mathrm{e}}$.

The exponents $b_{\mathrm{e}}, b_{\mathrm{c}}$, and $b_{\mathrm{m}}$ are the degree of mass dependence, respectively, on $Q_{e}, c$, and $q_{\max }$. It seems reasonable to assume that these exponents vary mainly between species and higher taxonomic groups, whereas the coefficients $a_{\mathrm{e}}, a_{\mathrm{c}}$, and $a_{\mathrm{m}}$ also vary with the environment.

\section{Model Predictions}

Optimal $M$ and $P,\left\{M^{*}, P^{*}\right\}$, are points on the trade-off curve, $M=h(P)$, with maximum fitness, $W$, and may be found numerically. Figure 1 shows the model predictions for a given parameterization of the fitness function and several trade-off curves corresponding to variable $Q_{e}(M)$, the energetic requirements of maintaining a given $M$.

Rate of energy expenditure $(Q)$, or DEE, of free-living animals may be measured by the doubly labeled water technique (Speakman 1997a). The following general predictions about the relationship between optimal body mass, $M^{*}$, and equilibrium rate of energy expenditure at optimal body mass, $Q^{*}=Q_{e}\left(M^{*}\right)=Q_{a}\left(M^{*}, P^{*}\right)$, follow from the following model.

Prediction 1: Influence of Energy Constraints When Assimilation Is Below Maximum. When animals do not assimilate energy at their maximum rate (in the lower interval of $P$; eq. [6]; fig. 1C), the slope of the trade-off curves (eq. [8]; fig. $1 D)$ for given values of the exponent $1 /\left(b_{\mathrm{e}}-b_{\mathrm{c}}\right)$ are determined by $a_{\mathrm{c}} / a_{\mathrm{e}}$. In environments with lower food quality or availability, less energy may be assimilated with the same foraging time (i.e., $a_{\mathrm{c}}$ becomes lower), and more energy is required to maintain a given $M$ (i.e., $a_{\mathrm{e}}$ becomes higher because more energy must be expended to obtain and digest food). The environment could also be energetically demanding due to predator stress and low temperatures (see below). Due to the lower slope of the tradeoff curve in energetically more demanding environments, optimal body mass $\left(M^{*}\right)$ will decrease whereas optimal time spent foraging $\left(P^{*}\right)$ will increase, resulting in a higher 

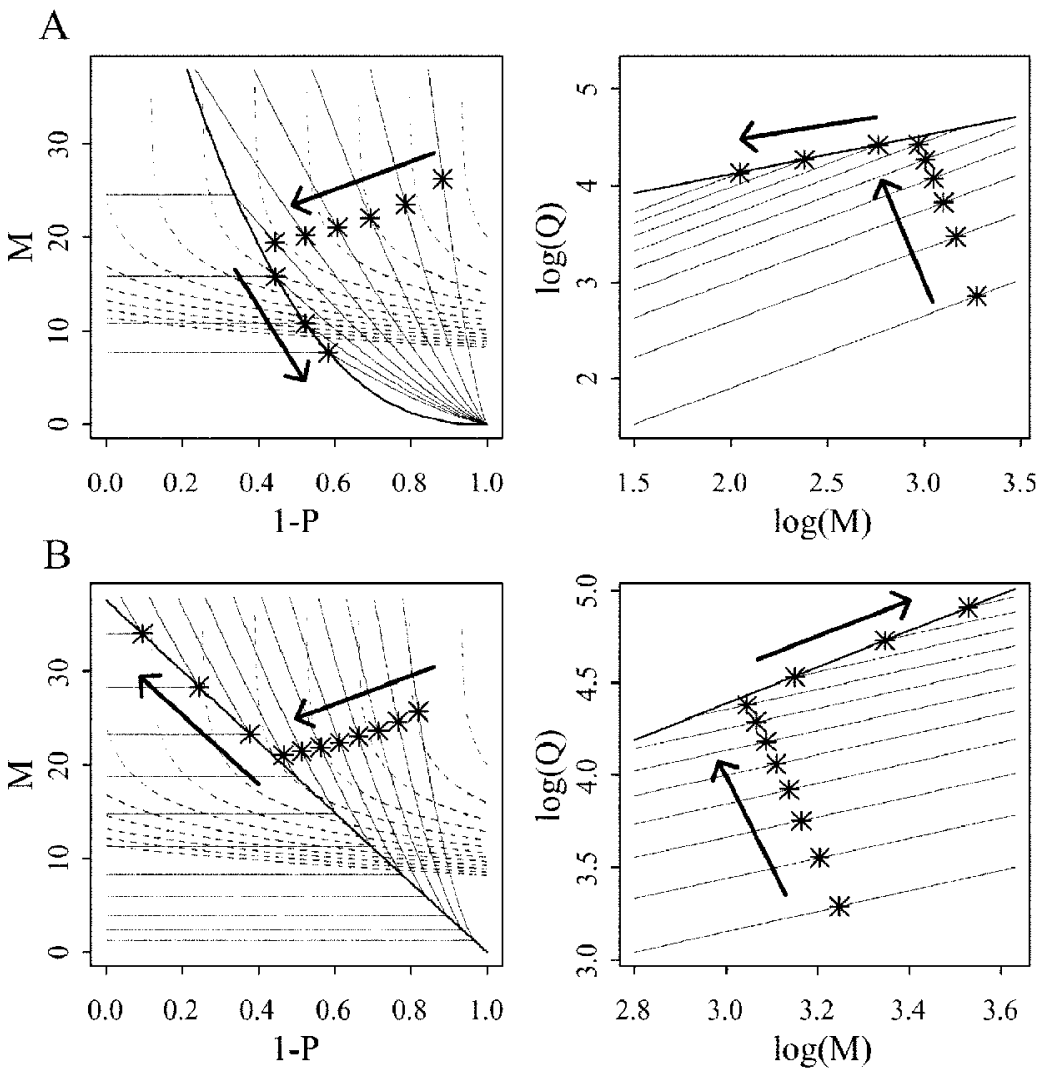

Figure 2: Model predictions when $(A) b_{\mathrm{e}}>b_{\mathrm{m}}$ and $(B) b_{\mathrm{m}}>b_{\mathrm{e}}$ (see explanation in fig. $1 D, 1 E$ ). Arrows indicate the change in the optimality points when energy demands $\left(a_{\mathrm{e}}\right)$ increase. Parameter values are the same as in figure 1 except that in $A, a_{\mathrm{e}}=\{1.5,3.0, \ldots, 13.5\}, b_{\mathrm{m}}=0.4$, and $a_{\mathrm{m}}=$ $100 / 25^{b_{\mathrm{m}}}$, and in $B, a_{\mathrm{e}}=\{4.5,6.0, \ldots, 19.5\}, b_{\mathrm{e}}=0.55, b_{\mathrm{m}}=0.99$, and $a_{\mathrm{m}}=100 / 25^{b_{\mathrm{m}}}$.

energy expenditure at $\left\{M^{*}, P^{*}\right\}$. Hence, when comparing environments with different food quality (or variable $a_{\mathrm{c}} / a_{\mathrm{e}}$ in general), a negative correlation between body mass $\left(M^{*}\right)$ and energy expenditure $\left(Q^{*}\right)$ should be observed as long as maximum energy expenditure $\left(q_{\max }\right)$ is not reached (fig. 1E).

Prediction 2: Influence of Energy Constraints When Assimilation Is at Maximum. If the energy demands of the environment at $M^{*}, Q_{\mathrm{e}}\left(M^{*}\right)$ increase beyond the point where animals are able to respond with an increase in energy assimilation (i.e., in the upper interval of $P$ where $q_{\max }$ is reached), then energy expenditure at $M^{*}$ is given by $q_{\max }=a_{\mathrm{m}} M^{b_{\mathrm{m}}}$. In this case, the effect of a higher $a_{\mathrm{e}}$ on $M^{*}$ depends on the sign of the exponent $1 /\left(b_{\mathrm{e}}-b_{\mathrm{m}}\right)$ (eq. [8]). If $b_{\mathrm{e}}>b_{\mathrm{m}}$, then a higher $a_{\mathrm{e}}$ will give a lower $M^{*}$, whereas if $b_{\mathrm{m}}>b_{\mathrm{e}}$, then a higher $a_{\mathrm{e}}$ will give a higher $M^{*}$. These two situations are shown in figure 2. Note that a positive correlation between $Q^{*}$ and $M^{*}$ is predicted in both of these situations when $q_{\max }$ is reached. Note also that, in the case where $b_{\mathrm{m}}>b_{\mathrm{e}}, M$ cannot be maintained below $M^{*}$ (individuals with $M<M^{*}$ will always have $Q_{\mathrm{a}}$ below $Q_{\mathrm{e}}$ and will eventually die from starvation).

Prediction 3: Influence of Survival Costs of Foraging. If the survival cost of foraging increases (lower $s_{\mathrm{f}}$ relative to $s_{\mathrm{n}}$ ), then fitness becomes more sensitive to $P$, as illustrated in figure $3 \mathrm{~A}$. Because of the steeper slope of the fitness isoclines at intermediate $M$, both $M^{*}$ and $P^{*}$ on a given tradeoff curve decrease as $s_{\mathrm{f}}$ becomes smaller. Hence, if variation in $M^{*}$ is due to optimal adjustments of foraging time in response to variation in predation risk when foraging, then a positive correlation between $M^{*}$ and $Q^{*}$ should occur (fig. 3B).

Prediction 4: Influence of Temperature. Decreasing ambient temperature may reduce survival at low $M$ (see first paragraph of "The Model"). Shifting $S_{\mathrm{m}}(M)$ in equation (2) to the right (fig. $1 A$ ) by decreasing $a_{\mathrm{s}}$ will increase the level of the fitness isoclines (eq. [4]), resulting in a higher $M^{*}$ (i.e., Bergmann's rule; see "Discussion"). However, lower temperature also imposes higher energetic costs and hence 
A

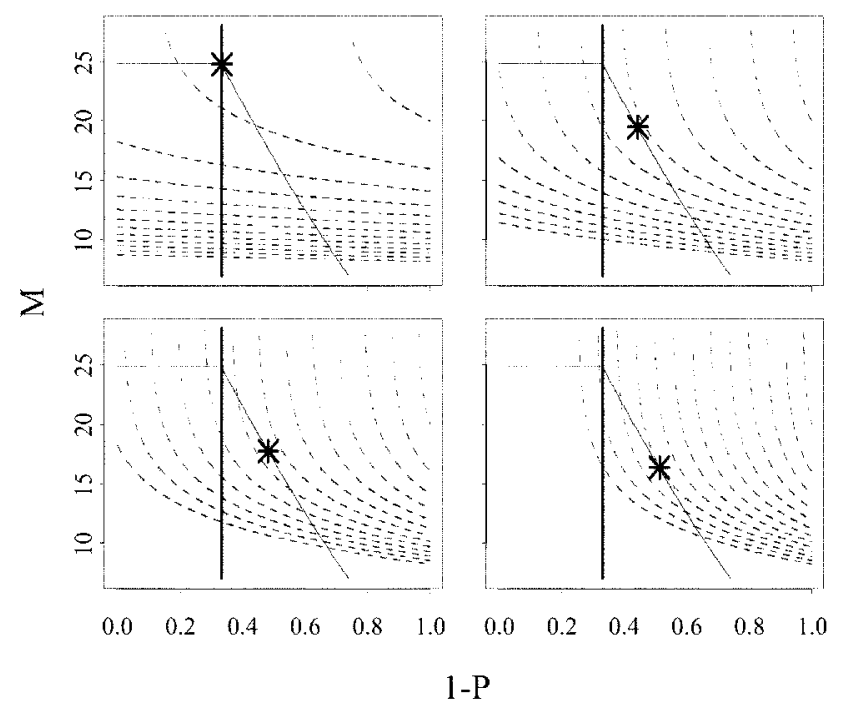

B

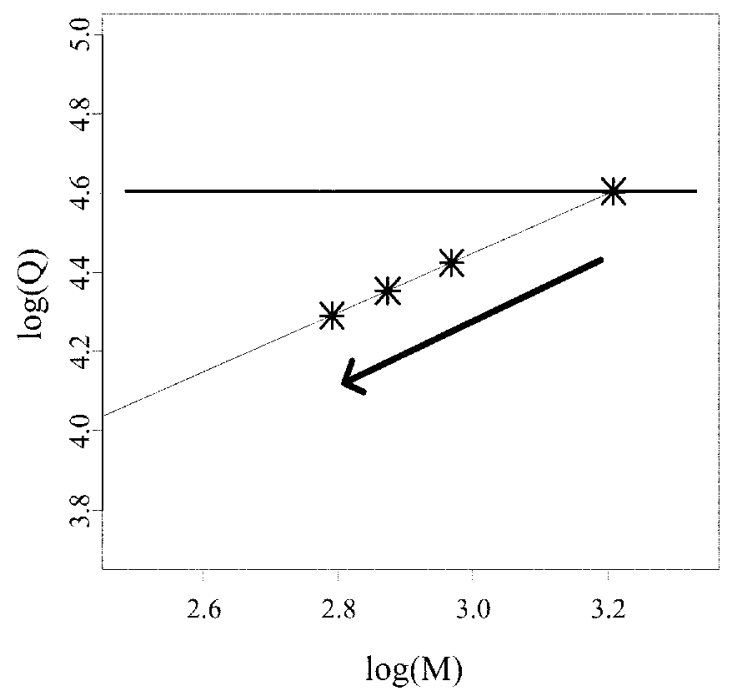

Figure 3: $A$, Predicted optimal body mass $\left(M^{*}\right)$ and foraging time $\left(P^{*}\right)$ with the same energetic constraints (trade-off curve) in four different environments with respect to survival costs of foraging (decreasing values of $s_{\mathrm{f}}$ from top left to bottom right by row). $B$, Predicted relation between $\log \left(Q^{*}\right)$ and $\log \left(M^{*}\right)$. Arrow indicates increasing survival cost of foraging (decreasing $\left.s_{\mathrm{f}}\right)$. See explanation in figure $1 D$, $1 E$. Parameter values are the same as in figure 1 except $s_{\mathrm{f}}=\{0.99,0.98,0.97,0.96\}$ and $a_{\mathrm{e}}=9.0$.

increases $Q_{\mathrm{e}}(M)$; see equation (5). An increase in $Q_{\mathrm{e}}(M)$ will lead to a lower $M^{*}$ except when $q_{\max }$ is reached in cases where $b_{\mathrm{m}}>b_{\mathrm{e}}$ (see "Prediction 1" and "Prediction 2 "). Hence, whereas $Q^{*}$ will always increase with lower ambient temperature, $M^{*}$ may either increase or decrease when the surroundings become colder depending on the exact effects of temperature on $S_{\mathrm{m}}(M)$ and $Q_{\mathrm{e}}(M)$.

In summary, the model predicts qualitatively different relationships between $Q^{*}$ and $M^{*}$ when different mechanisms are responsible for the variation in $M^{*}$ between environments. When variation in $M^{*}$ is due to variable trade-off curves between $M$ and $P$, there should be a negative correlation between $Q^{*}$ and $M^{*}$ when $Q^{*}<q_{\max }$ ("Prediction 1") and a positive (or zero) correlation when $Q^{*}=q_{\max }$ ("Prediction 2"). A positive correlation is also predicted when $M^{*}$ and $P^{*}$ are optimally adjusted to variations in the survival costs of foraging ("Prediction 3"). Below, we use these predictions to assess hypotheses regarding variation in overwintering body mass and energy expenditure in subpopulations of voles.

\section{Data}

In a recent field experiment where field voles (Microtus agrestis, L.) were transplanted among four locations that differed in average overwintering body mass of resident voles (by about 18\%), Ergon et al. (2001) showed that body mass of transplanted voles during midwinter converged toward the average mass at the site to which they were moved. Thus, the variation in wintering body mass among these sites reflected plastic individual responses to the immediate environment rather than differences in the population structure with respect to fixed individual states such as age, genetic composition, or persistent maternal effects (Ergon et al. 2001). We now report on a concurrent study on the DEE of the wintering voles (February) at these four sites in the same year. To evaluate general mechanisms that may be responsible for variation in body mass between these sites, we compare the observed associations between DEE and body mass $(M)$ within and between sites to the predictions of the above model. In particular, we assess two working hypotheses.

Hypothesis 1. Between-site differences in body mass were due to variation in the energetic constraints, determined by the energy demands of maintaining a given body mass (i.e., variation in $a_{\mathrm{e}}$ ) and/or in the body-mass specific rate of energy assimilation during the time spent foraging (i.e., variation in $a_{c}$; see "Prediction 1" and "Prediction 2").

Hypothesis 2. Between-site differences in body mass were due to behavioral responses to variation in the anticipated survival cost of foraging ( $s_{\mathrm{f}}$ relative to $s_{\mathrm{n}}$; see "Prediction 3").

Variation in the energetic demands and rate of energy assimilation during foraging (hypothesis 1) could be due 
Table 1: Details of the sampling sites

\begin{tabular}{|c|c|c|c|c|c|c|c|c|}
\hline Site & $\begin{array}{l}\text { Distance } \\
\text { from } \\
\text { A }(\mathrm{km})\end{array}$ & $\begin{array}{l}\text { Distance } \\
\text { from } \\
\text { B }(\mathrm{km})\end{array}$ & $\begin{array}{l}\text { Distance } \\
\text { from } \\
\mathrm{C}(\mathrm{km})\end{array}$ & $\begin{array}{l}\text { Distance } \\
\text { from } \\
\mathrm{D}(\mathrm{km})\end{array}$ & $\begin{array}{c}\text { Average body mass in } \\
\text { sampling period }^{\mathrm{a}}(\mathrm{g}) \\
\pm \mathrm{SE}\end{array}$ & $\begin{array}{c}\text { Date when } 50 \% \text { of } \\
\text { females had mated }^{\mathrm{b}} \\
\pm \mathrm{SE}\end{array}$ & $\begin{array}{l}\text { Biweekly } \\
\text { survival rate } \\
\text { of females } \\
\quad \pm \mathrm{SE}\end{array}$ & $\begin{array}{c}\text { Population } \\
\text { density }^{\mathrm{d}} \\
\left(\text { voles }^{-1} \mathrm{ha}^{-1}\right) \\
\text { February-May } \\
\text { (\% reduction) }\end{array}$ \\
\hline A & & 4 & 20 & 20 & $18.70 \pm .26$ & April $9 \pm 4.2$ days & $.80 \pm .03$ & $72-12(84 \%)$ \\
\hline B & 4 & & 21 & 22 & $20.87 \pm .23$ & March $18 \pm 4.3$ days & $.90 \pm .02$ & $99-69(30 \%)$ \\
\hline C & 20 & 21 & & 1 & $20.01 \pm .20$ & March $30 \pm 4.2$ days & $.82 \pm .02$ & 109-61 (44\%) \\
\hline $\mathrm{D}$ & 20 & 22 & 1 & & $20.08 \pm .19$ & March $27 \pm 3.8$ days & $.87 \pm .02$ & $183-107(42 \%)$ \\
\hline
\end{tabular}

to differences in food quality and predator-induced stress (see "Discussion"), whereas differences in the survival costs of foraging (hypothesis 2) would be due to differences in predator densities (perceived as, e.g., predator odors) or habitat characteristics.

According to hypothesis 1 , the association between equilibrium energy expenditure $\left(Q^{*}\right)$ and optimal body mass $\left(M^{*}\right)$ between the sites should be qualitatively different from the association within sites (see "Prediction 1" and "Prediction 2"). Whenever animals do not assimilate energy at their maximum rates (due to survival costs of foraging), one should, under hypothesis 1, expect a negative correlation between sites even when there is a positive correlation within sites ("Prediction 1").

As illustrated by our model, it should be optimal to reduce the proportion of time spent foraging $(P)$ when predation risk is high, leading to both a lower body mass $\left(M^{*}\right)$ and a lower equilibrium energy expenditure $\left(Q^{*}\right.$; see "Prediction 3" and fig. 3). Hence, according to hypothesis 2, a positive association between $M^{*}$ and $Q^{*}$ should occur. If there are no differences in $a_{\mathrm{e}}$ and $a_{\mathrm{c}}$ between sites (hypothesis 1), then the association between average body mass and average energy expenditure at the site level should be the same as the within-site association (see "Prediction 3").

\section{Material and Methods}

\section{Study System}

The study was carried out in Kielder Forest $\left(55^{\circ} 13^{\prime} \mathrm{N}\right.$, $2^{\circ} 33^{\prime} \mathrm{W}$ ), a large fragmented spruce plantation on the border between Scotland and England. Here, fluctuating subpopulations of field voles inhabit distinct clear cuts surrounded by dense tree stands that are unsuitable for voles (Lambin et al. 2000 for description). Vole populations fluctuate asynchronously over a relatively small spatial scale in this area (Lambin et al. 1998; MacKinnon et al. 2001). The study took place during February 1999 on four 1-ha trapping grids following an experiment in which voles had been transplanted between sites the previous November/ December (Ergon et al. 2001). The populations at the four sites were monitored by capture-mark-recapture live trapping (Williams et al. 2002) biweekly from February through May, which revealed large differences in onset of spring reproduction and survival between sites (table 1) as well as differences in population growth (Ergon et al. 2001).

Snow and frost spells never lasted more than a few days, and the ground was only occasionally covered by snow at the study sites. Temperature varied between $-8^{\circ} \mathrm{C}$ (minimum night temperature) and $16^{\circ} \mathrm{C}$ (maximum day temperature) during the study period (February). The most abundant vole predators in the study area are common weasels (Mustela nivalis, L.), red foxes (Vulpes vulpes, L.), tawny owls (Strix aluco, L.), and European kestrels (Falco tinniculus, L.; O'Mahony et al. 1999; Lambin et al. 2000; Petty et al. 2000; Graham and Lambin 2002). Pathogens are also highly prevalent in the study populations (Cavanagh et al. 2002).

\section{Field Procedures}

We measured DEE of free-living voles using the doubly labeled water (DLW) technique (Lifson and McClintock 1966; Speakman 1997a). Daily energy expenditure was measured only in females (all nonbreeding), and the samples included both transplanted and nontransplanted voles.

Voles were sampled using Ugglan traps at 7-m spacing, set at dusk (7-8 P.M.), and checked the following morning at dawn (7-8 A.M.). The traps were baited with carrots and barley, and hay was provided for bedding. Upon cap- 
ture, an initial blood sample $(\sim 50 \mu \mathrm{L})$ was taken by tail tipping for background isotope analysis. Animals were injected intraperitoneally with $0.3 \mathrm{~mL}$ DLW (10\% APE enriched ${ }^{18} \mathrm{O}$ water [Enritech, Rehovot, Israel] and 99\% APE enriched ${ }^{2} \mathrm{H}$ water [MSD Isotopes, Pointe-Claire, Quebec, Canada] mixed in a ratio of $20: 1$ ), left in the trap for 60 min, and then bled again to obtain an initial blood sample for isotope analysis. Voles were thereafter released at the exact location of capture. No attempt was made to recapture injected animals until the following morning, thus maximizing the amount of time the voles spent in natural field conditions. Twelve Longworth traps centered on the site where the vole was initially captured were set before dawn (6-7 A.M.) in an attempt to recapture individuals after approximately $24 \mathrm{~h}$. Traps were then checked at 23-h intervals throughout that day. In the event that a vole had not been recaptured in the first $36 \mathrm{~h}$ ( $20 \%$ of cases, same ability to trap in all sites), traps were left set overnight to maximize chances of recapture within $48 \mathrm{~h}$. Recaptured voles were bled and weighed for a second time and released at the exact location of capture.

Temperature was measured at ground level below the grass cover and recorded by a data logger at 30-min intervals. For each individual we calculated the mean of the recorded temperatures within the time between release after injection and recapture.

\section{Isotope Analysis}

Blood samples were distilled using the pipette method of Nagy (1983). Mass spectrometric analysis of deuterium enrichment was performed using $\mathrm{H}_{2}$ gas, produced from the distilled water after reaction with $\mathrm{LiAlH}_{4}$ (Ward et al. 2000). Reactions were performed inside 10-mL Vacutainers (Beckton Dickinson) as detailed by Krol and Speakman (1999). For analysis of ${ }^{18} \mathrm{O}$ enrichment, distilled water was equilibrated with $\mathrm{CO}_{2}$ gas using the small sample equilibration technique (Speakman 1997a). Preweighed Vacutainers were injected with $10 \mu \mathrm{L}$ of distilled water and reweighed $( \pm 0.0001 \mathrm{~g})$ to correct for differences in the amount of water added. Subsequently the Vacutainers with the samples were injected with $0.5 \mathrm{~mL} \mathrm{CO}_{2}$ with a known oxygen isotopic enrichment and left to equilibrate at $60^{\circ} \mathrm{C}$ for $16 \mathrm{~h}$. The rations ${ }^{2} \mathrm{H}:{ }^{1} \mathrm{H}$ and ${ }^{18} \mathrm{O}:{ }^{16} \mathrm{O}$ were measured using dual inlet gas source isotope ratio mass spectrometers (Optima, Micromass IRMS) with isotopically characterized gases of $\mathrm{H}_{2}$ and $\mathrm{CO}_{2}$ (CP grade gases, BOC) in the reference channels.

We estimated $\mathrm{CO}_{2}$ production using the single pool deuterium equation from Speakman (1997a). The error in individual estimates was determined using the iterative procedures outlined in Speakman (1995). Conversion to average DEE was made using an assumed respiratory quo- tient of 0.8 . All calculations were made using the Natureware DLW software (Speakman and Lemen 1999).

\section{Statistical Analysis, Candidate Models, and Multimodel Inference}

The aim of the data analysis was to study the relationship between body mass $(M)$ and DEE within and between the four study sites (table 1) and thereby assess our working hypotheses (see the introduction). The individual-level (within-site) relationship between $M$ and DEE was modeled explicitly, and the between-site association was assessed by plotting the fitted mean DEE against mean $M$ at the four sites. Because the effects of ambient temperature (T) may obscure or confound the effects on DEE, we included this variable in the analysis.

The relationship between DEE and $M$ is customarily modeled with an exponential function (e.g., Reiss 1989). Including the effect of $T$ as a multiplicative term, we used the general model DEE $=\alpha_{i} M^{\beta_{\mathrm{m}}} e^{\beta_{\mathrm{T}} T+\varepsilon}$, where $\alpha_{i}$ may take different values for each of the sites $(i=1, \ldots, 4)$ and where $\varepsilon$ is a normally distributed independent error with zero mean. Models were fitted with linear least squares regression of log-transformed data, $\log (\mathrm{DEE})=$ $\log \left(\alpha_{i}\right)+\beta_{\mathrm{m}} \log (M)+\beta_{\mathrm{t}} T+\varepsilon$. This regression gave homogenous residuals on our data.

Hypothesis 1 is logically consistent with models including different intercepts $\left(\log \left[\alpha_{i}\right]\right)$ for the four sites. However, lack of statistical support for such models could also be due to sparse data and weak effects. Hence, one would also need to view the confidence intervals (CIs) of any "site" effect to be able to claim support for hypothesis 2 .

Considering only additive models, we obtained eight candidate models (table 2), which we compared within the framework of the "information-theoretic approach" of observational inference (Anderson et al. 2000; Burnham and Anderson 2002). For each of the candidate models we calculated the Akaike's Information Criterion corrected for small-sample bias, $\mathrm{AIC}_{c}$, which is an estimate of relative difference between the conceptual high-dimensional "truth" and the approximating model (the KullbackLiebler [K-L] distance) and embodies the principle of parsimony (finding the optimal trade-off between low bias [generally complex models] and high precision [generally simple models]). For least square fits, the $\mathrm{AIC}_{\mathrm{c}}$ is given by

$$
\mathrm{AIC}_{\mathrm{c}}=n \log _{\mathrm{e}}\left(\frac{\mathrm{RSS}}{n}\right)+2 K+\frac{2 K(K+1)}{n-K-1}
$$

where $n=$ sample size, RSS $=$ residual sum of squares, and $K=$ total number of estimated parameters including intercept and residual variance. We further ranked the 
Table 2: All candidate models of $\log (\mathrm{DEE})$ ranked according to their $\mathrm{AIC}_{\mathrm{c}}$ value

\begin{tabular}{llcccc}
\hline & \multicolumn{1}{c}{ Terms } & $\begin{array}{c}\text { No. parameters } \\
\text { Model (rank) }\end{array}$ & \multicolumn{1}{c}{ Akaike } \\
\hline 1 & Site & 5 & .256 & .00 & .395 \\
2 & Site $+\log (M)$ & 6 & .295 & .62 & .290 \\
3 & Site $+\operatorname{Temp}$ & 6 & .262 & 2.47 & .115 \\
4 & Site $+\log (M)+$ Temp & 7 & .300 & 3.30 & .076 \\
5 & Constant & 2 & .000 & 4.39 & .044 \\
6 & Temp & 3 & .054 & 4.51 & .042 \\
7 & $\log (M)+$ Temp & 4 & .076 & 6.05 & .019 \\
8 & $\log (M)$ & 3 & .017 & 6.06 & .019 \\
\hline \multicolumn{2}{l}{ Note: $M=$ body mass, Site $=$ sampling site (factor), and Temp $=$ temperature. All models include an } \\
intercept. The residual variance $\left(\sigma^{2}\right)$ is counted as a parameter in $K . R^{2}$-adj. is the estimated proportion of \\
variance explained. See "Material and Methods" for the interpretation of the Akaike weights.
\end{tabular}

models by the "Akaike weights" calculated as model likelihoods scaled to sum to 1 ,

$$
w_{i}=\frac{e^{(-1 / 2) \Delta_{i}}}{\sum_{r=1}^{R} e^{(-1 / 2) \Delta_{r}}},
$$

where $\Delta_{i}$ is the $\mathrm{AIC}_{\mathrm{c}}$ value of the $i$ th model subtracted the lowest $\mathrm{AIC}_{\mathrm{c}}$ value among the $R=8$ candidate models. The weights $w_{i}$ can be interpreted as the approximate probabilities that model $i$ is the model with the lowest K-L distance in the set of candidate models. We used these weights to calculate weighted averages of the model predictions and parameter estimates as well as their unconditional variances incorporating uncertainty in the model selection (Burnham and Anderson 2002). These weights may also be summed across subsets of the models to obtain relative "importance weights" of specific effects (Burnham and Anderson 2002, pp. 167-169). Variance estimates of nonlinear-derived estimates were calculated by the " $\delta$ method" (Morgan 2000).

\section{Results}

We obtained in total 40 measurements of DEE of female voles at two sampling occasions at each of the four study sites (table 1) between February 1 and February 26. The first parturitions occurred around April 1 at some of the sites (Ergon et al. 2001). Hence, since the gestation period of field voles is about $19 \mathrm{~d}$, the last DEE measurements were taken at least two weeks before first conception (overwintering female voles do not initiate spring growth until they conceive the first litter; see "Discussion"). Both transplanted and nontransplanted voles (Ergon et al. 2001) were included in the samples. However, since "source" population before transplant did not have a significant effect (additive to the "site" effect) on the variation in either body mass ( $F=0.15$, df $=3,204, p=.68)$ or measure- ments of $\log$ DEE $(F=2.10, \mathrm{df}=3,33, p=.12)$, the "source" effect is ignored in the following presentation.

Average body mass of all immature females at the study sites during the study period ranged from $18.7 \mathrm{~g}$ (site A) to $20.9 \mathrm{~g}$ (site B; table 1). Although the difference was only $2.2 \mathrm{~g}(\mathrm{SE}=0.3)$, or $11.6 \%(\mathrm{SE}=2.0)$ of the average at site $\mathrm{A}$, and the distributions overlapped, the variation in mean body mass between the sites significantly departed from random $(p<.0001)$. In addition to having the smallest overwintering size, voles at site A had the lowest mean individual growth rate over the following spring (Ergon et al. 2001), the latest onset of breeding, and the lowest survival rates, and the population declined drastically during the spring $(84 \%$ reduction $[\mathrm{SE}=0.9]$ in $14 \mathrm{wk}$; table 1). In contrast, voles at site B matured about 3 wk earlier in the spring and had the highest survival rates among the four study sites (table 1).

Measurements of DEE varied nearly fourfold from 57 $\mathrm{kJ} \mathrm{d}^{-1}(0.66 \mathrm{~W})$ to $208 \mathrm{~kJ} \mathrm{~d}^{-1}(2.41 \mathrm{~W})$. The data and sampling protocol are shown in figure A1 in the online edition of the American Naturalist, and the ranking of the candidate models are given in table 2 .

The "site" effect (three parameters) is clearly a more important predictor of DEE than both $\log (M)$ (one parameter) and temperature (one parameter; importance weights of $0.88,0.40$, and 0.25 , respectively; see "Material and Methods"). The model averaged fitted predictions of these models and the unconditional standard errors are shown in figure 4. Absolute energy expenditure DEE was highest at site $\mathrm{A}$, where mean body mass was lowest, and DEE was lowest at site B, where voles had the highest body mass. Mean DEE of immature females at site A was 50\% higher than the mean at site B (95\% CI: 15\%, 96\%; model 1) despite the smaller average mass of these voles and a positive correlation between DEE and body mass within sites. This pattern is consistent with hypothesis 1 : the between-site differences in body mass were due to variable 


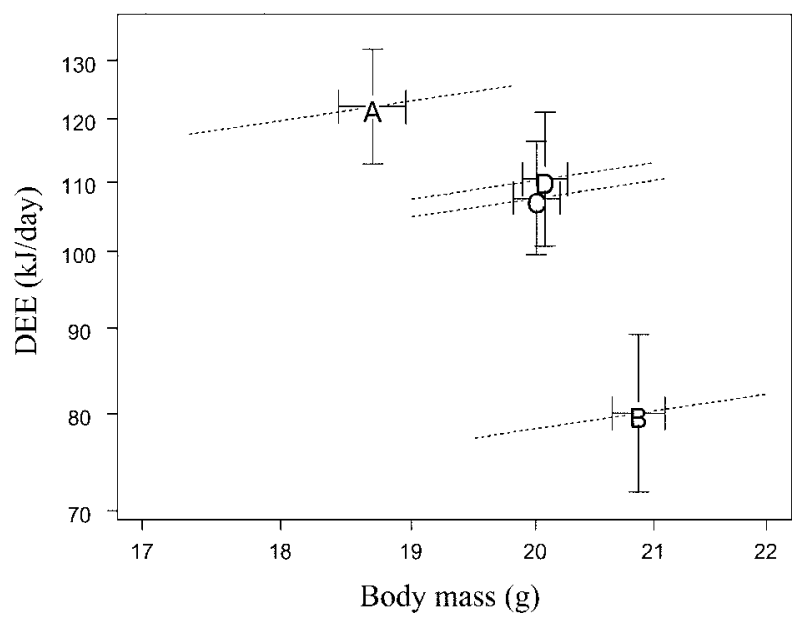

Figure 4: Mean daily energy expenditure (DEE; \pm SE) versus average body mass $( \pm \mathrm{SE})$ of immature females at the four study sites $(A-D)$. Fitted predictions of DEE ( $Y$-axis) are obtained by weighted model averaging (see "Material and Methods") of the candidate models that include a "site" effect (models 1-4, table 2). Predictions are for the overall mean value of temperature $\left(3.7^{\circ} \mathrm{C}\right)$ and the mean body mass at each of the sites (value on $X$-axis). Error bars show unconditional SEs (see "Material and Methods"). Stippled lines show the fitted slope to body mass within sites (weighted average of models 2 and 4 , table 2), ranging from the first to the third quartile of the distribution.

energetic constraints. The low proportion of the variance in the DEE measurements explained (only $25.6 \%$ by the $\mathrm{AIC}_{\mathrm{c}}$ best model) is as expected, given our methods and sampling design (see "Discussion").

We did not obtain any precise estimates of the effects of temperature and body mass $(M)$ on DEE due to the low range of the variation in these predictor variables within sites (fig. A1). Daily energy expenditure was estimated to be proportional to $M$ to the power of 0.50 (unconditional $\mathrm{SE}=0.36$, model averaging of models 2 and 4), and an increase in temperature by $1^{\circ} \mathrm{C}$ decreased DEE by $0.3 \%$ ( $95 \%$ CI: $8.1 \%,-8.2 \%$, model averaging of models 3, 4, 6, and 7).

\section{Discussion}

We compared DEE in four sites of wintering field voles that differed in average body mass and life-history traits of individuals as well as in population growth. A transplant experiment preceding this study at the same sites showed that during midwinter, voles reduced their body mass when moved to a site where resident voles had lower body mass and increased body mass when moved to a site where residents had higher body mass (Ergon et al. 2001). Survival, body growth, and reproductive development also converged to the values prevailing at the target sites.
We found that measurements of absolute energy expenditure of wintering females were highest at the site where average body mass was the lowest. This was despite a positive correlation between DEE and body mass within sites. Voles in this site also had the lowest individual growth rates, the latest onset of spring reproduction, and the lowest survival, and densities declined drastically during the following spring (table 1; Ergon et al. 2001). Such a negative correlation between body mass and DEE is predicted by our model when energetic costs of maintaining a given body mass differ between sites and animals do not assimilate energy at their maximum rate due to survival costs of foraging ("Prediction 1"). Hence, our data support the hypothesis that voles became smaller in the "decline site" (site A) because they expended more energy to avoid survival costs at small body mass (hypothesis 1) and not because they restricted energy ingestion to avoid survival costs due to predation when foraging (hypothesis 2). Although we are basing this inference on only four sampling sites studied in one year, our results suggest a large difference in the correlations between body mass and DEE at two sampling scales-opposite signs within and between sites-which is consistent with our model predictions.

The low proportion of the variance in the DEE measurements explained by the fitted models (only $25.6 \%$ by the $\mathrm{AIC}_{\mathrm{c}}$ best model) is not surprising. Much of the unexplained variance is presumably due to day-to-day variation in energy expenditure of the voles as well as interindividual differences in the metabolic rate, and considerable measurement error is associated with the DLW method (Berteaux et al. 1996; Speakman et al. 1994; Speakman 1997a). Since body mass is a major determinant of DEE (Speakman 1997b), studies including a larger range in body mass will naturally explain a larger proportion of the variance.

\section{Causes of Variation in the Energetic Constraints}

One probable reason for increased energy expenditure in the "decline site" is that high-quality food was less available in this site, and the voles therefore had to spend more energy obtaining and digesting food (see prediction 1 in "Model Predictions"). Energy availability in the vegetation may vary due to both qualitative and quantitative changes in the food plants, for example, reduction in plant biomass due to heavy grazing (e.g., Bergeron and Jodin 1993), fluctuations in the plant demography (Tast 1984; Bernard 1990), and induced plant resistance (reviewed by Herms and Mattson 1992; Karban and Baldwin 1997).

An alternative explanation could be that voles expended more energy on predator avoidance or because of predator-induced chronic stress (Boonstra et al. 1998) in the "decline site." More energy spent on escaping pred- 
ators, or due to nonadaptive stress, would also require an increased energy intake and hence a higher foraging activity, which may cause an even higher exposure to predation. However, if the voles face a higher risk of being predated while foraging, a better strategy would generally be to reduce activity (Lima 1998a, 1998b). In fact, a number of laboratory and enclosure studies suggest that this is the strategy that voles adopt: voles reduce foraging activity when confronted with predator odors and subsequently loose weight-probably as a consequence of reduced food intake (Desy and Batzli 1989; Ylönen 1994; Koskela and Ylönen 1995; Carlsen 1999; Perrot-Sinal et al. 2000). The result of this strategy would be lower energy expenditure when predation risk is high (hypothesis 2) and, according to our model, a positive correlation between DEE and body mass at the site level (fig. 3).

We do not know whether the reduced body mass at the energetically more demanding sites was the result of a nonadaptive starvation process or a more controlled adaptive response to severe energy constraints, as seems to be the case when voles reduce body mass as a response to shorter day length before the winter (see introduction). However, if there were no survival costs of foraging, or if the animals did not adjust their time spent foraging according to such costs, then animals should always assimilate energy at their maximum rate, and a positive correlation between mean energy expenditure and mean body mass at the sites should occur (see prediction 2 in "Model Predictions"). Hence, it appears that the voles in the less energetically demanding sites (especially site B) must have responded to a relaxation in the energetic constraints by reducing foraging time. Such a response may, however, have evolved as a fixed strategy to a general level of predation risk. Future studies may reveal whether individual small rodents perceive and respond to variations in the predation risk during winter and early spring. Our results, however, suggest that voles were smaller in the declining population because of a response to reduced food quality rather than to increased predation risk.

\section{Wintering Body Mass and Onset of Spring Reproduction}

In our model we assumed that postwinter reproductive value is independent of wintering body mass. This may not be the case if individuals that maintain a larger size during winter are able to initiate spring growth and reproduction earlier than smaller individuals. Such a tradeoff between optimal body size for survival and larger size enabling earlier reproduction seems plausible given that male voles have both larger overwintering body masses and an earlier onset of spring growth, as well as lower winter survival, than females in the same population (Ergon et al. 2001; Jackson et al. 2001; Aars and Ims 2002).
Life-history theory predicts that optimal trade-offs should be shifted toward earlier maturation and higher reproductive effort in increasing populations (Roff 1992). Likewise, an earlier commencement of the breeding season should be optimal when extrinsic prebreeding winter survival is lower (Ergon 2003). Hence, if voles have evolved adaptive responses to reliable cues about the population development or their future survival chances, then optimal reproductive strategies could potentially be responsible for between-year variation in overwintering body mass in multiannually fluctuating populations. Indeed, the differences in wintering body mass in our study were associated with large variation in the onset of spring reproduction (table 1; Ergon et al. 2001). However, if the animals in "increase sites" maintain a larger body mass to enable early reproduction despite the increase in energetic costs (and survival costs) that this would entail, then a positive correlation between body mass and DEE between sites should be observed. Hence, such a mechanism cannot explain the between-site variation in body mass in our study.

There are also reasons to believe that the trade-off between a small overwintering body mass and early spring reproduction has less significance: although grass-eating microtines have an energetically constrained food supply in the winter (see below), grasses are much more nutritious and digestible during their rapid growth season in the spring (Herms and Mattson 1992; Vicari and Bazely 1993). This enables the overwintering voles to grow rapidly on their superabundant spring food supply (lush grass fields). Overwintering female voles conceive their first litter while still at premature size and then more than double their total body mass ( $>50 \%$ gain excluding embryos) during 3 wk of pregnancy (Lambin and Yoccoz 2001; this was also seen in the spring after the present study [T. Ergon, unpublished]). Hence, a difference in overwintering body mass of a few grams probably has only a marginal effect on the timing of first parturition of females. Males may, conversely, have benefits of a larger size in an intense competition for polygynous territories in the early spring (Ostfeld 1985; Ims 1987), which may explain their larger wintering size.

\section{Geographical Trends and Interspecific Comparisons}

Probably the most studied geographical character trend is Bergmann's rule, which states that individuals within species (or higher taxonomic groups) tend to be larger in colder climates (James 1970). This is true for many animal species, although there are also many species showing the opposite trend (McNab 1971; Ashton et al. 2000). Freckleton et al. (2003) recently showed that intraspecific correlations between temperature and body size between populations are consistently negative only for lager mammals 
$(>0.16 \mathrm{~kg})$, whereas among small mammal species the correlation coefficients differ largely from species to species. An often suggested selective advantage of larger body size in cold environments is that larger animals have a lower surface-to-volume ratio and hence a lower relative heat loss, and they will therefore spend a lower proportion of their total energy budget on thermogenesis. This energetic argument is too simplistic for several reasons (Speakman 1996). Perhaps most seriously, proportion of total energy budget used on thermogenesis is in itself a very poor measure of fitness. Selection should not favor low heat loss relative to total metabolic rate (i.e., large body size) if the maintenance of a large body mass results in lower survival or is prohibited by energetic constraints. Our model shows that when fitness relations to both body size and foraging activity as well as environmental influences on both energy expenditure and energy assimilation are considered, the effects of decreasing temperature on optimal body mass is not straightforward (see prediction 4 in "Model Predictions"). Specifically, if the increase in fitness due to thermoregulatory benefits of a larger body size is smaller than the fitness cost of maintaining the larger size, then it is not optimal to increase body size in a colder climate. Instead, the fitness disadvantages of increased energetic demands in a cold climate may be compensated for by reducing body size.

Ashton et al. (2000) noted that contrary to most mammals, five of five studied species of Microtus voles were smaller at higher latitudes. If the mechanism behind these geographical trends is of the same kind as the one responsible for the between-site variation in body mass in our study, then the smallest and northernmost vole populations should exhibit the highest absolute rates of energy expenditure DEE. However, we are not aware of any studies relating geographic trends in body size to DEE of small mammals.

Unlike most microtines, collared lemmings (Dicrostonyx groenlandicus, Traill) living in the high arctic grow larger instead of becoming smaller in the winter (Malcolm and Brooks 1993; Nagy et al. 1994). One possible mechanism leading to a larger winter size is illustrated in figure $2 B$ (see prediction 2 in "Model Predictions"): if $b_{\mathrm{m}}>b_{\mathrm{e}}$ and the animals assimilate energy at maximum rate $\left(q_{\max }\right)$, then optimal body mass $\left(M^{*}\right)$ increases as the energetic costs of the environment $\left(Q_{e}[M]\right)$ become more severe. However, a more probable explanation is that winter conditions impose a stronger effect on the mass dependent survival than on the mass dependent energetic constraints of this species (see prediction 4 in "Model Predictions"). First, collared lemmings show several morphological changes in addition to growth to a larger size that indicate that they are adapted to more extreme exposure to the cold winter conditions. These include development of long bifid claws for digging in the snow, the moult to a long and dense white pelage, and development of a rounder body shape that decreases heat loss (Reynolds and Lavinge 1988; Malcolm and Brooks 1993). Other microtines at high latitudes and altitudes stay most of the winter in the subnivean space where temperatures never fall much below freezing (Schmid 1984; Marchand 1996). Second, collared lemmings have a different diet than most other folivorous microtines and are probably less energetically stressed by the winter food conditions. Whereas Microtus voles and lemmings of the genus Lemmus feed largely on gramineous monocots (Batzli 1993; Hjältén et al. 1996), collared lemmings feed mainly on dicots, especially Salix shrubs and Dryas spp. (Batzli 1993). Monocot grasses are, apart from a rapid growth season, generally heavily defended with digestibility reducers (Howe and Westley 1988; Vicari and Bazely 1993), and most of the green biomass in grassland habitats disappears before the winter. Dicots, however, are more digestible to animals that can deal with their toxins (Batzli and Cole 1979; Howe and Westley 1988; Batzli 1993) and probably represent a more seasonally stable food source than grasses (Negus and Berger 1998).

Grass-eating microtines have evolved a large and efficient but energetically costly digestive system ( $\mathrm{McNab}$ 1986; Koteja and Weiner 1993), which adds to their constrained winter energy budget. Their large gut capacity may, however, enable the animals to assimilate larger amounts of energy when high-quality grass is abundant in the spring, facilitating a rapid growth and reproduction (see above). Clearly, to understand interspecific patterns as well as intraspecific and seasonal variations in body size of animals, one must consider many aspects of nutritional ecology and animal energetics as well as trophic interactions and life-history trade-offs. Our model provides a framework for such analyses.

\section{Acknowledgments}

This study was funded by the Natural Environment Research Council (to J.R.S. and X.L.) and the Norwegian Research Council (to T.E.). C. Griffin and K. Reid participated in the fieldwork. We thank J. Aars, W. Blanckenhorn, J. Durant, R. Ergon, E. Johannesen, H. Steen, and N. Chr. Stenseth for comments and discussion.

\section{Literature Cited}

Aars, J., and R. A. Ims. 2002. Intrinsic and climatic determinants of population demography: the winter dynamics of tundra vole populations. Ecology 83:34493456.

Anderson, D. R., K. P. Burnham, and W. L. Thompson. 2000. Null hypothesis testing: problems, prevalence, and 
an alternative. Journal of Wildlife Management 64:912923.

Ashton, K., M. Tracy, and A. de Queiroz. 2000. Is Bergmann's rule valid for mammals? American Naturalist 156:390-415.

Batzli, G. O. 1993. Food selection by lemmings. Pages 281301 in N. C. Stenseth and R. A. Ims, eds. The biology of lemmings. Academic Press, London.

Batzli, G. O., and F. R. Cole. 1979. Nutritional ecology of microtine rodents: digestibility and forage. Journal of Mammalogy 60:740-750.

Bergeron, J.-M., and L. Jodin. 1993. Intense grazing by voles (Microtus pennsylvanicus) and its effect on habitat quality. Canadian Journal of Zoology 71:1823-1830.

Bernard, J. M. 1990. Life history and vegetative reproduction in Carex. Canadian Journal of Botany 68:14411448.

Berteaux, D., D. W. Thomas, J. M. Bergeron, and H. Lapierre. 1996. Repeatability of daily field metabolic rate in female meadow voles (Microtus pennsylvanicus). Functional Ecology 10:751-759.

Blanckenhorn, W. U. 2000. The evolution of body size: what keeps organisms small? Quarterly Review of Biology 75:385-407.

Boonstra, R. 1989. Life history variation in maturation in fluctuating meadow vole populations (Microtus pennsylvanicus). Oikos 54:265-274.

Boonstra, R., and W. M. Hochachka. 1997. Maternal effects of additive genetic inheritance in the collared lemming Dicrostonyx groenlandicus. Evolutionary Ecology 11: 169-182.

Boonstra, R., and C. J. Krebs. 1979. Viability of large and small-sized adults in fluctuating vole populations. Ecology 60:567-573.

Boonstra, R., D. Hik, G. R. Singleton, and A. Tinnikov. 1998. The impact of predator-induced stress on the snowshoe hare cycle. Ecological Monographs 68:371394.

Bronson, F. H., and P. D. Heideman. 1994. Seasonal regulation of reproduction in mammals. Pages 541-583 in E. Knobil and J. D. Neill, eds. The physiology of reproduction. Raven Press, New York.

Burnham, K. P., and D. R. Anderson. 2002. Model selection and inference: a practical information-theoretic approach. Springer, New York.

Calder, W. A. 1984. Size, function and life-history. Harvard University Press, Cambridge, Mass.

Carlsen, M. 1999. The effects of predation risk on body weight in the field vole, Microtus agrestis. Oikos 87:277285.

Cavanagh, R., M. Begon, M. Bennett, T. Ergon, I. M. Graham, P. E. W. de Haas, C. A. Hart, et al. 2002. Mycobacterium microti infection (vole tuberculosis) in wild rodent populations. Journal of Clinical Microbiology 40: 3281-3285.

Chitty, D. 1952. Mortality among voles (Microtus agrestis) at Lake Vyrnwy, Montgomeryshire, in 1936-9. Philosophical Transactions of the Royal Society of London B 236:505-552.

Crowcroft, P., and J. M. Ingles. 1959. Seasonal changes in the brain-case of the common shrew (Sorex araneus L.). Nature 183:907-908.

Cuthill, I., and A. Houston. 1997. Managing time and energy. Pages 97-120 in J. Krebs and N. Davis, eds. Behavioural ecology: an evolutionary approach. Blackwell Science, Oxford.

Dark, J., and I. Zucker. 1983. Short photoperiods reduce winter energy requirements of the meadow vole, Microtus pennsylvanicus. Physiology \& Behavior 31:699-702.

Dehnel, A. 1949. Studies on the genus Sorex L., summary. Annales Universitatis Mariae Curie-Sklodowska Sectio C Biologia 4:17-97.

Desy, E. A., and G. O. Batzli. 1989. Effects of food availability and predation on prairie vole demography: a field experiment. Ecology 70:411-421.

Ergon, T. 2003. Fluctuating life-history traits in overwintering field voles (Microtus agrestis). Ph.D. thesis, Faculty of Mathematics and Natural Sciences, University of Oslo.

Ergon, T., X. Lambin, and N. C. Stenseth. 2001. Lifehistory traits of voles in a fluctuating population respond to the immediate environment. Nature 411:10431045.

Freckleton, R. P., P. H. Harvey, and M. Pagel. 2003. Bergmann's rule and body size in mammals. American Naturalist 161:821-825.

Gliwicz, J. 1996. Life history of voles: growth and maturation in seasonal cohorts of the root vole. Miscellánea Zoológica 19.1:1-12.

Gower, B. A., T. R. Nagy, and M. H. Stetson. 1994. Preand postnatal effects of photoperiod on collard lemmings (Dicrostonyx groenlandicus). American Journal of Physiology 267:R879-R887.

Graham, I. M., and X. Lambin. 2002. The impact of weasel predation on cyclic field-vole survival: the specialist predator hypothesis contradicted. Journal of Animal Ecology 71:946-956.

Hansen, T. F., and R. Boonstra. 2000. The best in all possible worlds? a quantitative genetic study of geographic variation in the meadow vole, Micotus pennsylvanicus. Oikos 89:81-94.

Hansson, L. 1990. Ultimate factors in the winter weight depression of small mammals. Mammalia 54:397-404.

- 1992. Fitness and life-history correlates of weight variations in small mammals. Oikos 64:479-484. . 1995. Size dimorphism in microtine rodent 
populations: characteristics of growth and selection against large-sized individuals. Journal of Mammalogy 76:867-872.

Hayes, J. P., J. R. Speakman, and P. A. Racey. 1992. The contributions of local heating and reducing exposed surface area to the energetic benefits of huddling by shorttailed field voles (Microtus agrestis). Physiological Zoology 65:742-762.

Herms, D. A., and W. J. Mattson. 1992. The dilemma of plants: to grow or to defend. Quarterly Review of Biology 63:283-335.

Hjältén, J., K. Danell, and L. Ericson. 1996. Food selection by two vole species in relation to plant growth strategies and plant chemistry. Oikos 76:181-190.

Howe, H. F., and L. C. Westley. 1988. Ecological relationships of plants and animals. Oxford University Press, New York.

Ims, R. A. 1987. Responses in spatial organization and behavior to manipulations of the food resource in the vole Clethrionomys rufocanus. Journal of Animal Ecology 62:585-596.

Iverson, S., and B. N. Turner. 1974. Winter weight dynamics in Microtus pennsylvanicus. Ecology 55:10301041.

Jackson, D. M., P. Trayhurn, and J. R. Speakman. 2001. Associations between energetics and over-winter survival in the short-tailed field vole Microtus agrestis. Journal of Animal Ecology 70:633-640.

James, F. 1970. Geographic size variation in birds and its relation to climate. Ecology 51:365-390.

Karban, R., and I. T. Baldwin. 1997. Induced responses to herbivory. University of Chicago Press, Chicago.

Kendall, W. L., K. H. Pollock, and C. Brownie. 1995. A likelihood-based approach to capture-recapture estimation of demographic parameters under the robust design. Biometrics 51:293-308.

Koskela, E., and H. Ylönen. 1995. Suppressed breeding in the field vole (Microtus agrestis): an adaptation to cyclically fluctuating predation risk. Behavioral Ecology 6: 311-315.

Koteja, P., and J. Weiner. 1993. Mice, voles and hamsters: metabolic rates and adaptive strategies in muroid rodents. Oikos 66:505-514.

Krebs, C. J., and J. H. Myers. 1974. Population cycles in small mammals. Advances in Ecological Research 8:267399.

Kriegsfeld, L. J., and R. J. Nelson. 1996. Gonadal and photoperiodic influences on body mass regulation in adult male and female prairie voles. American Journal of Physiology-Regulatory Integrative and Comparative Physiology 39:R1013-R1018.

Krol, E., and J. R. Speakman. 1999. Isotope dilution spaces of mice injected simultaneously with deuterium, tritium and oxygen-18. Journal of Experimental Biology 20: 2839-2849.

Lambin, X., and N. G. Yoccoz. 2001. Adaptive precocial reproduction in voles: reproductive costs and multivoltine life-history strategies in seasonal environments. Journal of Animal Ecology 70:191-200.

Lambin, X., D. Elston, S. Petty, and J. MacKinnon. 1998. Spatial patterns and periodic travelling waves in cyclic field vole, Microtus agrestis, populations. Proceedings of the Royal Society of London B 265:1491-1496.

Lambin, X., S. J. Petty, and J. L. MacKinnon. 2000. Cyclic dynamics in field vole populations and generalist predation. Journal of Animal Ecology 69:106-118.

Lifson, N., and R. McClintock. 1966. Theory of use of the turnover rates of body water for measuring energy and material balance. Journal of Theoretical Biology 12:4674.

Lima, S. L. 1998a. Nonlethal effects in the ecology of predator-prey interactions. BioScience 48:25-34.

- 1998b. Stress and decision-making under the risk of predation: recent developments from behavioral, reproductive and ecological perspectives. Advances in the Study of Behavior 28:215-290.

Lindstedt, S. L., and M. S. Boyce. 1985. Seasonality, fasting endurance, and body size in mammals. American Naturalist 125:873-878.

MacKinnon, J. L., S. J. Petty, D. A. Elston, C. J. Thomas, T. N. Sherratt, and X. Lambin. 2001. Scale invariant spatio-temporal patterns of field vole density. Journal of Animal Ecology 70:101-111.

Madison, D. M. 1984. Group nesting and its evolutionary significance in overwintering microtine rodents. Pages 267-274 in J. F. Merritt, ed. Winter ecology of small mammals. Carnegie Museum of Natural History, Pittsburgh.

Malcolm, J. R., and R. J. Brooks. 1993. The adaptive value of photoperiod-induced shape changes in the collared lemming. Pages 311-328 in N. C. Stenseth and R. A. Ims, eds. The biology of lemmings. Academic Press, London.

Marchand, P. J. 1996. Life in the cold. University Press of New England, Hanover, N.H.

McDevitt, R. M., and J. R. Speakman. 1994. Central limits to sustainable metabolic rate have no role in cold acclimation of the short-tailed field vole (Microtus agrestis). Physiological Zoology 67:1117-1139.

McNab, B. K. 1971. On the ecological significance of Bergmann's rule. Ecology 52:845-854.

. 1986. The influence of food habits on the energetics of eutherian mammals. Ecological Monographs 56:1-19.

Millar, J. S., and G. J. Hickling. 1990. Fasting endurance 
and the evolution of mammalian body size. Functional Ecology 4:5-12.

Morgan, B. J. T. 2000. Applied stochastic modelling: Arnold texts in statistics. Arnold, London.

Mrosovsky, N. 1978. Circannual cycles in hibernators. Pages 21-65 in L. C. H. Wang and J. W. Hudson, eds. Strategies in the cold: natural torpidity and thermogenesis. Academic Press, New York.

Nagy, K. A. 1983. The doubly labeled water $\left({ }^{3} \mathrm{HH}^{18} \mathrm{O}\right)$ method: a guide to its use. Laboratory of Biomedical and Environmental Sciences, University of California, Los Angeles.

Nagy, T. R., and N. C. Negus. 1993. Energy acquisition and allocation in male collared lemmings (Dicrostonyx groenlandicus): effects of photoperiod, temperature, and diet quality. Physiological Zoology 66:537-560.

Nagy, T. R., B. A. Gower, and M. H. Stetson. 1994. Photoperiod effects on body mass, body composition, growth hormone, and thyroid hormones in male collared lemmings (Dicrostonyx groenlandicus). Canadian Journal of Zoology 72:1726-1734.

Negus, N. C., and P. J. Berger. 1998. Reproductive strategies of Dicrostonyx groenlandicus and Lemmus sibiricus in high-arctic tundra. Canadian Journal of Zoology 76: 391-400.

Norrdahl, K., and E. Korpimäki. 2002. Changes in individual quality during a 3-year population cycle of voles. Oecologia (Berlin) 130:239-249.

Oksanen, L., and P. Lundberg. 1995. Optimization of reproductive effort and foraging time in mammals: the influence of resource level and predation risk. Evolutionary Ecology 9:45-56.

O’Mahony, D., X. Lambin, J. L. MacKinnon, and C. F. Coles. 1999. Fox predation on cyclic field vole populations in Britain. Ecography 22:575-581.

Ostfeld, R. S. 1985. Limiting resources and territoriality in microtine rodents. American Naturalist 126:1-15.

Perrot-Sinal, T., K. P. Ossenkopp, and M. Kavaliers. 2000. Influence of a natural stressor (predator odor) on locomotor activity in the meadow vole (Microtus pennsylvan$i c u s)$ : modulation by sex, reproductive condition and gonadal hormones. Psychoneuroendocrinology 25:259-276.

Petty, S. J., X. Lambin, T. N. Sherratt, C. J. Thomas, J. L. Mackinnon, C. F. Coles, M. Davison, and B. Little. 2000. Spatial synchrony in field vole Microtus agrestis abundance in a coniferous forest in northern England: the role of vole-eating raptors. Journal of Applied Ecology 37:136-147.

Reiss, M. 1989. The allometry of growth and reproduction. Cambridge University Press, Cambridge.

Reynolds, P. S., and D. M. Lavinge. 1988. Photoperiodic effects on body size and energetics of the collared lem- ming, Dicrostonyx groenlandicus. Canadian Journal of Zoology 66:835-841.

Roff, D. A. 1992. The evolution of life histories: theory and analysis. Chapman \& Hall, New York.

Schmid, W. D. 1984. Materials and methods for subnivean sampling. Pages 25-33 in J. F. Merritt, ed. Winter ecology of small mammals. Carnegie Museum of Natural History, Pittsburgh.

Sibly, R. M. 1991. The life-history approach to physiological ecology. Functional Ecology 5:184-191.

Speakman, J. R. 1995. Estimation of precision in DLW studies using the 2-point methodology. Obesity Research 3:31-39.

- 1996. Energetics and the evolution of body size in small terrestrial mammals. Symposia of the Zoological Society of London 69:63-81.

- 1997a. Doubly-labelled water: theory and practice. Chapman \& Hall, London.

. 1997b. Factors influencing the daily energy expenditure of small mammals. Proceedings of the Nutrition Society $56: 1119-1136$.

Speakman, J. R., and C. Lemen. 1999. Doubly-labelled water calculation program. Version 1.0. Natureware. http://www.abdn.ac.uk/ nhi158/enreshome.htm.

Speakman, J. R., P. A. Racey, A. Haim, P. I. Webb, G. T. H. Ellison, and J. D. Skinner. 1994. Inter- and intraindividual variation in daily energy expenditure of the pouched mouse (Saccostomus campestris). Functional Ecology 8:336-342.

Spears, N., and J. R. Clarke. 1988. Selection in field voles (Microtus agrestis) for gonadal growth under short photoperiod. Journal of Animal Ecology 57:61-70.

Taitt, M. J., and C. J. Krebs. 1985. Population dynamics and cycles. Pages 567-620 in R. H. Tamarin, ed. Biology of new world Microtus. Special publication, American Society of Mammalogists, no. 8. American Society of Mammalogists, Shippensburg, Pa.

Tast, J. 1984. Winter success of root voles, Microtus oeconomus, in relation to population density and food conditions at Kilpisjärvi, Finnish Lapland. Pages 59-66 in J. F. Merritt, ed. Winter ecology of small mammals. Carnegie Museum of Natural History, Pittsburgh.

Vicari, M., and D. R. Bazely. 1993. Do grasses fight back? the case for antiherbivore defences. Trends in Ecology \& Evolution 8:137-140.

Ward, S., M. Scantlebury, E. Krol, P. J. Thomson, C. Sparling, and J. R. Speakman. 2000. Preparation of hydrogen from water by reduction with lithium aluminium hydride for the analysis of delta $\mathrm{H}-2$ by isotope ratio mass spectrometry. Rapid Communications in Mass Spectrometry 14:450-453.

White, G. C., and K. P. Burnham. 1999. Program MARK: 
survival estimation from populations of marked animals. Bird Study 46(suppl):120-138.

Williams, B., J. Nichols, and M. Conroy. 2002. Analysis and management of animal populations. Academic Press, San Diego, Calif.
Ylönen, H. 1994. Vole cycles and antipredatory behaviour. Trends in Ecology \& Evolution 9:426-430.

Associate Editor: Nicolas Perrin 